\title{
Exploring the five-paced viper (Deinagkistrodon acutus) venom proteome by integrating a combinatorial peptide ligand library approach with shotgun LC-MS/MS
}

\author{
Xuekui Nie ${ }^{1}$ (D), Qiyi He ${ }^{1}$, Bin Zhou², Dachun Huang ${ }^{1}$, Junbo Chen ${ }^{1}$, Qianzi Chen ${ }^{1}$, Shuqing Yang ${ }^{3}$, Xiaodong Yu ${ }^{1 *}$ \\ ${ }^{1}$ Animal Toxin Group, Engineering Research Center of Active Substance and Biotechnology, Ministry of Education, College of Life Sciences, \\ Chongqing Normal University, Chongqing, China. \\ ${ }^{2}$ Library, Chongqing Normal University, Chongqing, China. \\ ${ }^{3}$ Emergency Department, Chongqing Emergency Medical Center, Chongqing University Central Hospital, Chongqing, China.
}

\section{Keywords:}

Combinatorial peptide

ligand library

Deinagkistrodon acutus

Snake venom

Venomics

Trace toxins

\begin{abstract}
Background: Snake venoms are complex mixtures of toxic proteins or peptides encoded by various gene families that function synergistically to incapacitate prey. In the present study, in order to unravel the proteomic repertoire of Deinagkistrodon acutus venom, some trace abundance components were analyzed.

Methods: Shotgun proteomic approach combined with shotgun nano-LC-ESI-MS/ MS were employed to characterize the medically important $D$. acutus venom, after collected samples were enriched with the combinatorial peptide ligand library (CPLL). Results: This avenue helped us find some trace components, undetected before, in $D$. acutus venom. The results indicated that $D$. acutus venom comprised 84 distinct proteins from 10 toxin families and 12 other proteins. These results are more than twice the number of venom components obtained from previous studies, which were only 29 distinct proteins obtained through RP-HPLC for the venom of the same species. The present results indicated that in D. acutus venom, the most abundant components (66.9\%) included metalloproteinases, serine proteinases, and C-type lectin proteins; the medium abundant components (13\%) comprised phospholipases $\mathrm{A}_{2}\left(\mathrm{PLA}_{2}\right)$ and 5'-nucleotidases and nucleases; whereas least abundant components $(6 \%)$ were aminopeptidases, L-amino acid oxidases (LAAO), neurotoxins and disintegrins; and the trace components. The last were undetected before the use of conventional shotgun proteomics combined with shotgun nano-LC-ESI-MS/MS, such as cysteine-rich secretory proteins $\mathrm{Da}-\mathrm{CRPa}$, phospholipases B-like 1, phospholipases B (PLB), nerve growth factors (NGF), glutaminylpeptide cyclortransferases (QC), and vascular non-inflammatory molecules 2 (VNN2). Conclusion: These findings demonstrated that the CPLL enrichment method worked well in finding the trace toxin proteins in D. acutus venom, in contrast with the previous venomic characterization of D. acutus by conventional LC-MS/MS. In conclusion, this approach combined with the CPLL enrichment was effective for allowing us to explore the hidden $D$. acutus venomic profile and extended the list of potential venom toxins.
\end{abstract}

\footnotetext{
* Correspondence: yxd@cqnu.edu.cn https://doi.org/10.1590/1678-9199-JVATITD-2020-0196 Received: 25 December 2020; Accepted: 18 March 2021; Published online: 25 October 2021
} 


\section{Background}

The five-paced viper, also known as the Chinese moccasin (Deinagkistrodon acutus, once named as Agkistrodon acutus), is a unique member of the monotypic genus Deinagkistrodon of the Viperidae family, reaching up to $2 \mathrm{~m}$ in length and weighing over $5 \mathrm{~kg}$. It is a highly venomous snake in China and its venom's $\mathrm{LD}_{50}$ ranges from $0.04 \mathrm{mg} / \mathrm{kg}$ to $10.0 \mathrm{mg} / \mathrm{kg} \mathrm{SC}$ [1]. Most toxins in its venom are responsible for coagulopathy in the envenomation caused by $D$. acutus bites.

Undoubtedly, unraveling the biochemical composition of $D$. acutus venom is of great importance for understanding the molecular mechanism of envenoming led by its bites. Like other snake venoms, $D$. acutus venom is also a mixture of bioactive compounds, containing enzymes, non-enzyme proteins, and polypeptides with a wide variety of sequence motifs, which are essential for binding important physiological molecular targets with high affinity to kill or immobilize preys [2].

Before the emerging of proteomic and transcriptomic methodology and technology, most studies on the venom of $D$. acutus were focused on the individual components with biochemical characteristics, and several components have been described including metalloproteinases [3,4], phospholipases $\mathrm{A}_{2}$ [5,6], serine proteases [7,8], C-type lectin-like proteins [9], and other polypeptides with promising biological functions $[9,10]$. However, researches on a single component of snake venom do not completely reveal the clear composition of $D$. acutus venom.

To access the global profile of $D$. acutus venom at the molecular level, Qinghua et al. [2] adopted the strategy of large-scale expressed sequence tags (ESTs) sequencing from the venom gland of D. acutus cDNA library. They identified the transcripts that may represent a general panorama of the physiological events taking place in the venom glands, and surveyed gene expression from the very specialized secretory tissue, especially for those involved in coagulopathy [2]. In 2016, they sequenced the genome and transcriptome of the five-paced viper and conducted comparative genomic analyses[11]. The above-mentioned works will help solve the global composition of the five-paced viper venom.

With the advances of 2-DE, HPLC, and MS/MS techniques, the proteome of several snake venoms were profiled in the reported documents. Shotgun proteomic approach combined with LC-MS/MS is a viable, highly sensitive, and high-throughput technique that provides rapidly a global profile of the protein and polypeptide components in a complex biological sample, such as protein mixture (snake venom) [12], cells [13], tissues, and organs [14].

Recently, to enrich the components with low abundance in biological samples, the combinatorial peptide ligand library (CPLL) method was used to explore the global protein profiles in many biological samples, including human urine [15] and serum [16], human platelets [17], human erythrocytes [18], chicken egg white [19] and yolk [20], and plant tissues [21]. The CPLL consists of a solid-phase combinatorial library of hexapeptides synthesized via a short spacer on poly (hydroxy methacrylate) beads according to the modified Merrifield approach [22], each bead displaying the same hexapeptides distributed throughout the core of the pearl. The ligand density can achieve a density of ca. $40-60 \mathrm{mmol} / \mathrm{mL}$ bead volume, and the complete library may contain a set of millions of different hexapeptides.

CPLL beads reduce the dynamic range of the proteome by simultaneously diluting high-abundance proteins and concentrating low-abundance ones. Especially in the field of animal venomics, CPLL was used to unravel the global protein profiles of venoms in several venomous animals, such as honeybee (Apis mellifera) [23], Crotalus atrox [24] that led to the discovery of some trace protein components previously undetected.

In the current work, we firstly explored an in-depth analysis of venomic of $D$. acutus by CPLL combined with shotgun nano-LCESI/MS/MS, which revealed a clear feature of protein distribution in $D$. acutus venom, which will facilitate to understand the mechanism of envenoming caused by $D$. acutus bites.

\section{Methods}

\section{Venom collection}

The adult snakes (D. acutus) with an average length of about $60 \mathrm{~cm}$ were captured in Wulingshan Mountain, Chongqing, China. The snake venoms were milked and lyophilized, then stored at $-80^{\circ} \mathrm{C}$ until further use.

\section{Protein enrichment by CPLL}

Two hundred $\mathrm{mg}$ of lyophilized venom was dissolved in $3 \mathrm{~mL}$ of Tris- $\mathrm{HCl}$ buffer ( $\mathrm{pH} 7.2$, including $50 \mathrm{mM} \mathrm{KCl}$ ) at room temperature overnight. The sample was centrifuged at 13,000 $\times$ $\mathrm{g}$ for $10 \mathrm{~min}$, then the supernatant was incubated with $100 \mu \mathrm{L}$ of ProteoMiner ${ }^{\text {twx }}$ beads (Catalog \# 163-3009, Bio-Rad Laboratories, Inc, USA) pre-equilibrated with the same buffers, shaking for 3 $h$ at room temperature. Subsequently, the non-specific absorbed proteins were removed by 3 rounds of washing using $10 \mathrm{mM}$ $\mathrm{NaH}_{2} \mathrm{PO}_{4}$ buffer ( $\mathrm{pH} 7.4$, including $150 \mathrm{mM} \mathrm{NaCl}$ ), finally, the captured proteins left on beads were eluted out using $200 \mu \mathrm{L}$, $100 \mu \mathrm{L}$, and $100 \mu \mathrm{L}$ elution reagent (8 M urea, $2 \%$ CHAPS), respectively, and all the eluates were pooled to a protein concentration, as determined by Bradford protein assay (Thermo Scientific Pierce, Hudson, NH, USA).

\section{SDS-PAGE}

The lyophilized venom and the eluate fraction with the same amount (approximately $40 \mu \mathrm{g}$ ) were loaded on $12 \%$ Tris-glycine SDS-PAGE in a Mini protean 3 system (Bio-Rad Laboratories, Hercules, CA, USA), running at $140 \mathrm{~V}$. After electrophoresis, the gel was stained with colloidal coomassie blue.

\section{In-solution digestion}

Protein digestion was performed according to the FASP procedure described by Wiśniewski et al. [25]. Briefly, the protein sample (about $30 \mu \mathrm{g}$ ) was solubilized in $30 \mu \mathrm{L}$ SDT buffer 
(4\% SDS, $100 \mathrm{mM} \mathrm{DTT,} 150 \mathrm{mM}$ Tris- $\mathrm{HCl} \mathrm{pH} 8.0$ ) at $90^{\circ} \mathrm{C}$ for $5 \mathrm{~min}$. The detergent, DTT, and other low-molecular-mass components were removed using $200 \mu \mathrm{L}$ UA buffer (8 M Urea, $150 \mathrm{mM}$ Tris- $\mathrm{HCl} \mathrm{pH} \mathrm{8.0)} \mathrm{by} \mathrm{repeated} \mathrm{ultrafiltration} \mathrm{(Microcon}$ units, $3 \mathrm{kDa}$ ). Then $100 \mu \mathrm{L} 0.05 \mathrm{M}$ iodoacetamide in UA buffer was added to block reduced cysteine residues and the samples were incubated for $20 \mathrm{~min}$ in darkness. The filter was washed with $100 \mu \mathrm{L}$ UA buffer three times and then with $100 \mu \mathrm{L} 25 \mathrm{mM}$ $\mathrm{NH}_{4} \mathrm{HCO}_{3}$ twice. Finally, the protein suspension was digested with $2 \mu$ g trypsin (Promega) in $40 \mu \mathrm{L} 25 \mathrm{mM} \mathrm{NH}_{4} \mathrm{HCO}_{3}$ overnight at $37^{\circ} \mathrm{C}$, and the resulting peptides were collected as a filtrate.

\section{LC-ESI-MS/MS}

Experiments were performed on a Q Exactive mass spectrometer that was coupled to Easy nano-LC (Proxeon Biosystems, now Thermo Fisher Scientific). A label-free quantification method (Q exactive) was used to achieve relative quantification by comparing the intensity of mass spectral peaks of different peptides. Six microliters of each fraction was injected for nano-LC-ESI-MS/ MS analysis. The peptide mixture $(5 \mu \mathrm{g})$ was loaded onto the C18 reversed-phase column (Thermo Scientific Easy Column, $10 \mathrm{~cm}$ long, $75 \mu \mathrm{m}$ inner diameter, $3 \mu \mathrm{m}$ resin) in buffer $\mathrm{A}(0.1 \%$ formic acid) and separated with a linear gradient of buffer $\mathrm{B}(80 \%$ acetonitrile and $0.1 \%$ formic acid) at a flow rate of $250 \mathrm{~nL} / \mathrm{min}$ controlled by IntelliFlow technology over 140 mins. MS data were acquired using a data-dependent top10 method dynamically choosing the most abundant precursor ions from the survey scan (300-1800 m/z) for HCD fragmentation. The determination of the target value is based on predictive Automatic Gain Control (pAGC). The dynamic exclusion duration was $60 \mathrm{~s}$. Survey scans were acquired at a resolution of 70,000 at $\mathrm{m} / \mathrm{z} 200$ and resolution for HCD spectra was set to $17,500 \mathrm{at} \mathrm{m} / \mathrm{z} 200$. The normalized collision energy was $30 \mathrm{eV}$ and the underfill ratio, which specifies the minimum percentage of the target value likely to be reached at maximum fill time, was defined as $0.1 \%$. The instrument was run with peptide recognition mode enabled.

\section{Sequence database searching and data analysis}

MS/MS spectra were interpreted by using the Mascot search engine (Matrix Science, London, UK; version 2.2). The proposed peptide sequences were compared with nonredundant databases of snake venomous proteins generated from data compiled at the UniProtKB/Swiss-Prot and UniProtKB/TrEMBL (score $\geq$ 20). For protein identification, the following options were used. Peptide mass tolerance $=20 \mathrm{ppm}, \mathrm{MS} / \mathrm{MS}$ tolerance $=0.1 \mathrm{Da}$, Enzyme $=$ Trypsin, Missed cleavage $=2$, Fixed modification: Carbamidomethyl (C), Variable modification; Oxidation(M). The high-confidence proteins were determined by the standard of unique peptide count $\geq 2$.

\section{Results}

\section{Protein compounds of venom treated with CPLL}

The CPLL pretreatment decreased the dynamic range of the venom sample (Figure 1). The two most abundant proteins, such as snake venom metalloproteinase (SVMP) and serine protease (SVSP), were diminished in the elution fraction compared to the crude venom sample. From the SDS-PAGE pattern, we observed an enrichment protein band at around $17 \mathrm{kDa}$, which might contain a large number of $17 \mathrm{kDa}$ protein family members, like C-type lectin. Besides, the three novel protein bands were found in the elution fraction. Further highlighting the usefulness of the combinatorial peptide library approach as a complementary tool of classical protocols is essential for lessening the high abundant compounds and concentrating the low-abundance and trace proteins from the complex venom proteomes.

\section{Identification of $D$. acutus venom proteins}

D. acutus venom proteins were dealt with CPLL followed by trypsin digestion directly, then the tryptic peptide fractions were analyzed using the nano-LC-ESI-MS/MS proteomics technique. A total of 583 unique tryptic proteins or peptides were identified from $D$. acutus venom samples (Additional file 1). Eighty-four unique proteins were high confidence determined by more than two unique peptides matched. The information regarding the identified proteins, such as the matched peptide sequences, accession number, theoretical pI, and molecular mass, their charge states, and $M / Z$ values, are given in (Additional file 1). This list includes 33 compounds found in venom protein and 44 compounds found in venom gland transcripts (Additional file 2). Besides, this study detected 47 new venom compounds in D. acutus venom, undetected before, which were also found in other species.

\section{Characterization of venom protein profile}

According to predicted amino acid sequences, the theoretical isoelectric point (pI) and molecular mass of the identified proteins were calculated using the computer $\mathrm{pI} /$ molecular mass tool (http:// cn.expasy.org/tools/pi_tool.html). There was an overview of the distribution of proteome components (Figure 2 and Figure 3 ) and showed that $54 \%(46 / 85)$ of the total proteins were distributed in a range of $\mathrm{pI} 5-6$, but proteins with $\mathrm{pI}>9$ or $\mathrm{pI}<4$ were never found. The molecular mass of the identified proteins was mainly distributed in $15 \mathrm{kDa}-30 \mathrm{kDa}(41.17 \%), 45 \mathrm{kDa}-60 \mathrm{kDa}$ (25.88\%), and $60 \mathrm{kDa}-75 \mathrm{kDa}(14.12 \%)$. Especially, the proteins from $15 \mathrm{kDa}$ to $75 \mathrm{kDa}$ were accounted for $85.88 \%(73 / 85)$, the proteins with greater than $90 \mathrm{kDa}$ accounted for $4.7 \%(4 / 85)$ and the proteins with lesser than $15 \mathrm{kDa}$ accounted for $8.24 \%(7 / 85)$. 


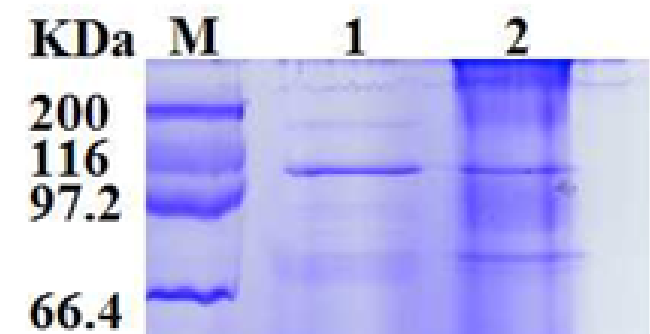

44.3

29

20.1

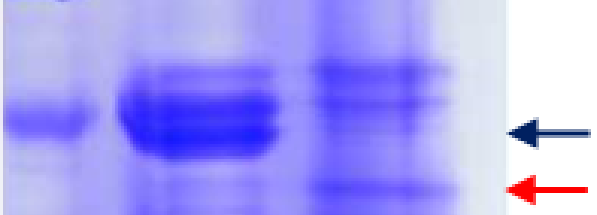

14.3

Figure 1. Electrophoretic separation of a combinatorial peptide ligand library (CPLL)-treated D. acutus venom sample. Crude D. acutus venom proteins (lane 1) and the elution fractions from CPLL (lane 2) were separated on a 12\% reduced Tris-glycine SDS-PAGE gel. Markers were a mass ladder of pure proteins from 6.5 to $200 \mathrm{kDa}$. All samples were loaded in $10 \mu \mathrm{L}$ volume ( $40 \mu \mathrm{g}$ of protein), staining with colloidal coomassie blue. Red arrows presented the concentrated components, black arrows presented the diminished components.

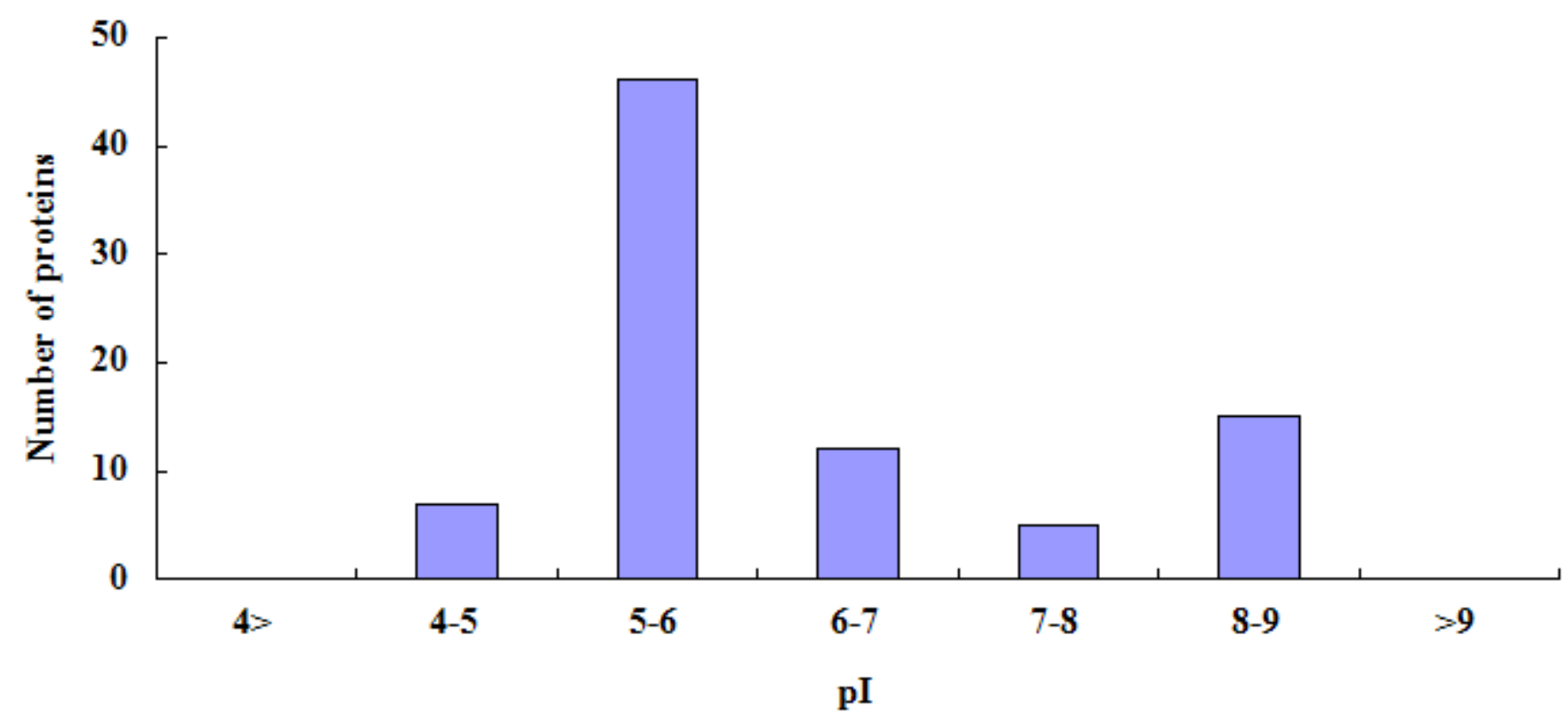

Figure 2. Distributions of isoelectric point ( $\mathrm{pl}$ ) of the high-confidence $D$. acutus venom proteins from the elution fraction from CPLL. 


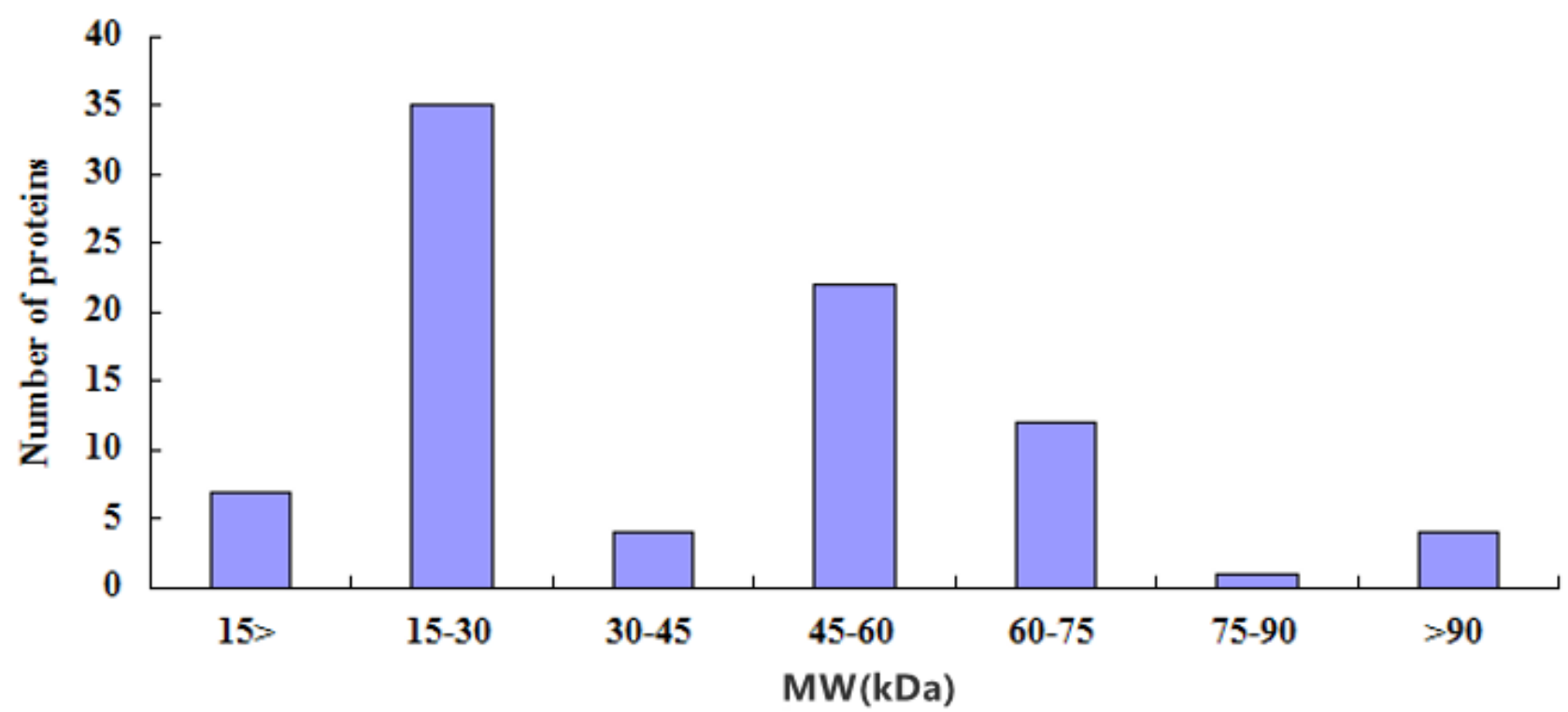

Figure 3. Distributions of the molecular mass of the high-confidence D. acutus venom proteins from the elution fraction from CPLL.

\section{Overall protein composition of $D$. acutus venom}

Identified $D$. acutus venom proteins belong to 10 groups of toxins (Figure 4, Table 1). The dominant protein families SVMPs (31.7\%), SVSPs (17.6\%), and C-type lectins (17.6\%), the medium-abundance families PLA $_{2}(4.7 \%), 5$ 'nucleotidase (5.9\%), and nuclease (2.4\%), and the low-abundance protein family aminopeptidase (1.2\%), LAAO (1.2\%), neurotoxin (1.2\%), disintegrin (2.4\%) amounting to $6 \%$ of the venom proteins. In the previous study, the venomic profile of $D$. acutus was composed of SVMPs (46.86\%), C-type lectins (37.59\%), PLA (7.33\%), SVSP (6.62\%), others (1.6\%) [26]. Furthermore, the trace proteins, undetected before by conventional shotgun proteomics combined with LC-MS/MS, such as cysteine-rich secretory protein $\mathrm{Da}-\mathrm{CRPa}$, phospholipase B-like 1, PLB, NGF, glutaminyl-peptide cyclortransferase (QC), and vascular noninflammatory molecule 2 .

\section{Discussion}

To further detect the low-abundance or trace components in $D$. acutus venom, we employed CPLL beads to treat the venom sample. Indeed, the $D$. acutus venom sample treated by CPLL beads displayed much more different molecular mass protein bands on Tris-glycine SDS-PAGE than the venom sample lack CPLL beads pretreatment (Figure 2), and the dominant components SVMP and serine protease were diminished in the venom [27], and the low-abundance components concentrated obviously. Thus, the CPLL pretreatment decreased the dynamic range of the $D$. acutus venom sample, extended its search towards the complete molecular mass range of the venom, and is an effective enrichment approach for detecting the low-abundance or trace components of venoms, as demonstrated in several previous reports, such as honeybee [23], Western diamondback rattlesnake [24] and African puff adder [22].
The CPLL couple to shotgun nano-LC-ESI-MS/MS allows us to explore $D$. acutus venomic. In total, 84 compounds were detected, which were categorized into 10 groups of toxins according to their putative function (Additional file 2). Among these, 32 compounds were found in venom protein and 44 compounds found in venom gland transcripts. The previous study about $D$. acutus venomic that 29 unique proteins or peptides had been identified using the shotgun digestion approach alone [26]. In our result, the protein family of the snake venom proteome and the members of the protein family were richer than previous reports [28], and we found that some dominant components (SVMP, C-type lectins, $\mathrm{PLA}_{2}$ ) were diminished and some component rich (SVSP) against previous studies. The most obvious variance between the previous and the present study was whether minor or trace components were discovered in the snake venom. We confirmed that our proposal was extremely valid. Meanwhile, the content of the main components showed significant differences, which may account for individual, geographical (habitats in Chongqing and Taiwan), age-related differences, CPLL [29-31]. Their biological function provides insights into venom toxicity. In snake venoms, components that are usually abundant are also functionally abundant, evolve more rapidly, and act on multiple targets [32]. Besides, snake injuries are often induced by the synergistic action of multiple snake venom components [33]. Our findings underscore the usefulness of combinatorial peptide libraries and shotgun nano-LC-ESI-MS/MS as powerful tools for visualization of venom proteomes. Through the combination of peptide library and mass spectrometry, a more comprehensive snake venomic was obtained, which helped to understand the molecular mechanism of D. acutus bites and guide the rational use and preparation of antivenom for snakebite.

As most viper snake venoms profile, $D$. acutus venom is mainly composed of SVMP, SVSP, C-type lectins, 5'-Nucleotidase, nuclease, $\mathrm{PLA}_{2}$ [34]. The pathological symptoms of D. acutus 
Table 1. Overview of the relative occurrence of proteins (in the percentage of all high-confidence D. acutus venom proteins from the elution fractions from CPLL) of the different families in the venom of D. acutus.

\begin{tabular}{|c|c|}
\hline Protein family & $\%$ of total venom proteins \\
\hline P I-SVMP & 8.2 \\
\hline P II-SVMP & 15.3 \\
\hline P III-SVMP & 8.2 \\
\hline C-type lectin & 17.6 \\
\hline SVSP & 17.6 \\
\hline 5'-nucleotidase & 5.9 \\
\hline $\mathrm{PLA}_{2}$ & 4.7 \\
\hline nuclease & 2.4 \\
\hline Disintegrin & 2.4 \\
\hline Aminopeptidase & 1.2 \\
\hline LAAO & 1.2 \\
\hline Neurotoxin & 1.2 \\
\hline Other proteins & 14.1 \\
\hline
\end{tabular}

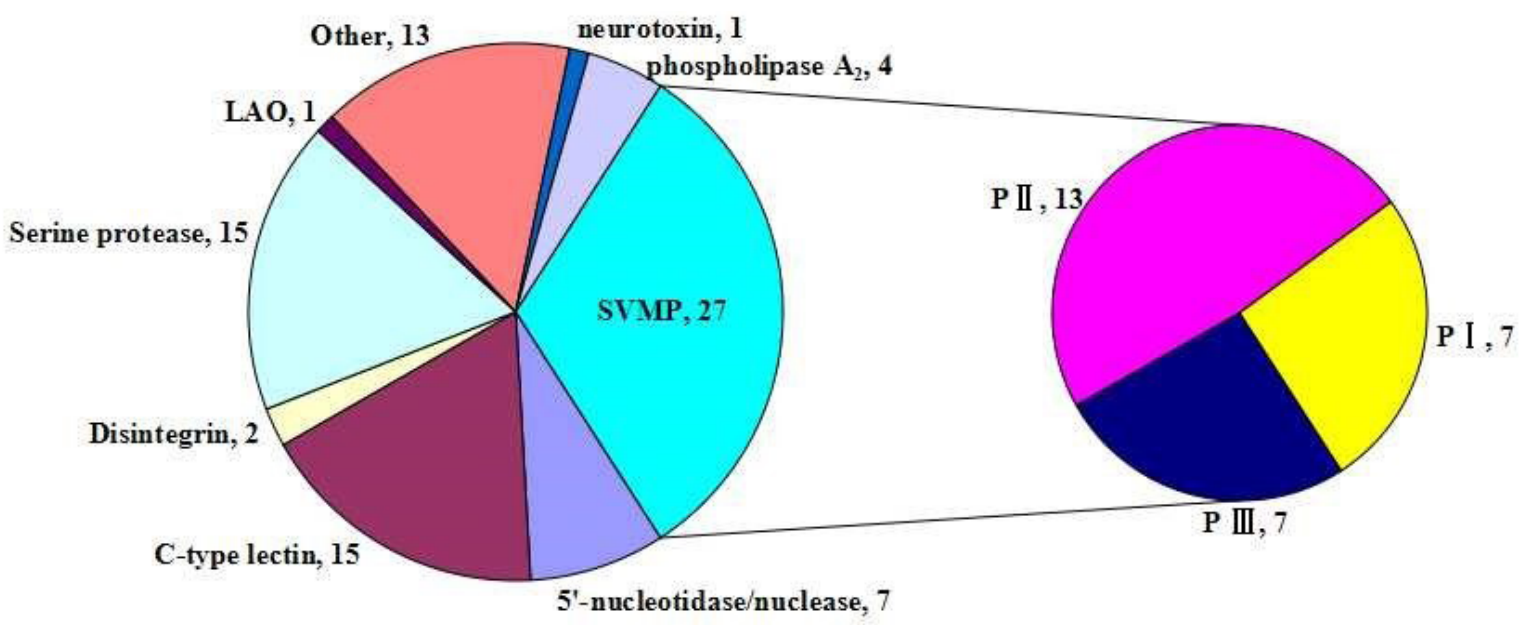

Figure 4. Overall protein composition of $D$. acutus venom. The relative number of different toxin families in all high-confidence proteins. $\mathrm{PI}$, $\mathrm{P}$ II, $\mathrm{P}$ III -SVMP, snake venom metalloproteinase from class I, II, and III; C-type lectin, C-type lectin-like protein; LAAO, L-amino acid oxidase.

envenomation showed severe coagulopathy and thrombocytopenia in addition to localized ulceration and systemic bleeding. However, these pathological symptoms are mainly related to SVMPs in D. acutus venom, which displays a wide range of biological activities affecting hemostasis, including hemorrhagic, fibrinolytic, activation of prothrombin, and Factor X31-33 [35]. The previous report confirmed that post-translational mechanisms and transcript alternative splicing can expand the diversity of functions and structure of SVMP [36]. Excluding SVMP, some other toxins and non-toxins components also contribute to snakebite damage. Fifteen serine proteases were found in the $D$. acutus venom, and 6 SVSPs had never been reported in $D$. acutus. Indeed, 13 types of serine protease were found in the transcripts of the $D$. acutus venom gland, the results indicate that the mRNAs experienced the post-transcriptional processing (alternative mRNA splicing) that guided the synthesis of SVSPs in snake venom. Alternative mRNA splicing was involved in the production of divergent gene transcripts in some other species, such as Habu Snake, Protobothrops flavoviridis [36]. Fifteen $\mathrm{C}$-type lectins were found and $3 \mathrm{C}$-type lectins had never been reported in D. acutus, surprisingly, 28 types of C-type lectin are found in the venom gland transcripts of D. acutus. C-type lectin affects thrombosis and hemostasis, and serine proteinases interfere in platelet aggregation, blood coagulation, and fibrinolysis [37]. The diverse and abundant snake venom families always play an indispensable role in snakebite morbidity and mortality.

The minor components are composed of disintegrin, PLB, phosphodiesterase (PDE), LAAO, NGF, aminopeptidase, glutaminyl-peptide cyclotransferase (QC), VNN2, cysteinerich secretory protein $\mathrm{Da}-\mathrm{CRPa}$, and neurotoxin. Disintegrins act as receptor antagonists, inhibiting platelet aggregation induced by ADP, thrombin, and collagen [38]. In our study, only 2 disintegrins were found, not including those derived from metalloproteinase. Noticeably, most of the disintegrins 
derived from metalloproteinase with disintegrin-like domains, especially P-II class metalloproteinase (metalloproteinasedisintegrin precursor) cleaved by protease (proteolytic enzyme in venom), illuminating the diversity of metalloproteinase (P-I) and disintegrin [39]. Hence, plentiful disintegrins might exist in snake venom. PLB can cleave ester linkages at the positions sn-1 and sn-2 of glycerophospholipids from cell membranes [39], and hydrolyze the second messengers CAMP and cGMP, to regulate their intracellular concentration and biological effects [40].

Previous reports indicate that PDE plays a role in envenomation by hydrolyzing DNA and RNA, releasing adenosine and other purine nucleotides [41], and induces a variety of pathological and pharmacological effects, such as vascular permeability, hypotension, platelet aggregation, edema, and paralysis [42]. LAAO (ACTX-6), isolated from D. acutus venom, showed substrate specificity, cytotoxicity, antitumor activity in vivo, and apoptosis-inducing activity [43]. As for the antioxidant and antibacterial activities of LAAO, maybe as a self-protection mechanism to avoid diseases caused by the pathogenic bacteria due to the feeding process [44]. Aminopeptidase contributes a significant role in kallikrein-kinin system (angiotensin III, angiotensin II) and causes hypotension [45,46], while the capacity of aminopeptidase $\mathrm{N}$ and aminopeptidase $\mathrm{A}$ are diverse in peripheral and central of humans. The fundamental role of leucine aminopeptidase (arylamidase) contains digestion, hypotension, and anticoagulation [47].

QC, containing a catalytically essential zinc ion, catalyzes the conversion of protein $\mathrm{N}$-terminal glutamine (or glutamic acid) residue into pGlu (pyroglutamate) and that is important during the maturation of many bioactive peptides, hormones, and proteins in their secretory pathway and also committed in cancer immunotherapy [48,49]. QC isolated from several animal and plant sources [50,51], and the genes coding for QC identified in numerous organisms [52,53], 8 snake venom QC protein sequences had been sequenced.

Mature PIII-SVMPs secreted into the venom proteome usually contain an $\mathrm{N}$-terminal pyroglutaminyl residue, suggesting that glutamyl cyclase plays an important role in the transformation of metalloproteinases precursors become mature metalloproteinases. VNN2 protein belongs to a novel glycosylphosphatidyl-inositol-anchored protein member of the VNN family (belongs to a wider pantetheinase family) that serves an important role in transendothelial migration of cells and participates in regulating neutrophil trafficking and adherence [54,55], also serve a role in redox regulation, which may be associated with tumor progression in vitro [56]. Therefore, the cancer suppression mechanism that includes VNN2 is not only limited to mammals, and the same mechanism may exist in the serpent. Using proteomic and transcriptomic approaches, VNN2 was identified in king cobra [57], and we hypothesize that VNN2 (V8N7Y3) was responsible for the post-translational modification (ubiquitination) of the snake venom proteome.

Unquestionably, snakebite envenomation syndrome attributes to the synergy of multiple toxic proteins or peptides. The minor abundant snake venom toxins activity to the wound adjacent target cell molecular, such as DNA, RNA, second messenger (cAMP, cGMP), so we confirm that secondary damages of snakebite may owe to the low abundant toxins [58]. Hence, we should not only focus on high-abundance components in snakebite treatment procedures, but trace components also should be taken seriously.

Snake venom is a treasure of potential drugs of protein or peptide origin. Snake venom-derived drugs currently in use or clinical trials are mainly used for the treatment of cardiovascular diseases. The non-addictive analgesic cobrotoxin from Naja atra; Captopril, an anti-hypertensive drug from Bothrops jararaca; Hemocoagulase from B. atrox for orthopedic surgery, abdominal surgery, and human vitrectomy; and a variety of drugs in clinical trials for acute peripheral arterial Alfimeprase from Agkistrodon contortrix, and A. rhodostoma for acute ischemic stroke [59]. And a variety of drugs have been isolated and purified from $A$. contortrix, including thrombolytic proteins [60], anticancer proteins [61]. With the application of "omics" technology in the process of snake venom research, we believe that a large number of snake venom proteins with potential drug value will be discovered one after another, and open up channels for the development of protein-based drug resources.

\section{Conclusion}

Snake venom is a cocktail of proteins and peptides and each component plays an indispensable role in predation and defense. Numerous studies are committed to figuring out the venom profile, exploiting the "traditional method", which did not detect the hidden or trace components in snake venom. The "omics method" comprises an intelligent alternative. The combination of the CPLL approach with nano-LC-ESI-MS/MS allows us to explore $D$. acutus venomics. In total, 84 compounds were detected, which were categorized into 10 different groups of toxins according to their putative function. Among these, 32 compounds were found from venom and 44 compounds were identified from venom gland transcripts. Their biological function provides insights into venom toxicity. The results underscore the usefulness of combinatorial peptide libraries and shotgun nano-LC-ESI-MS/MS as a powerful tool for visualization of venom proteome. Moreover, such combined method represents a powerful tool for tracing hidden components, and provides a guide for snakebite immunotherapy.

\section{Abbreviations}

CPLL: combinatorial peptide ligand library; ESTs: expressed sequence tags; LAAO: L-amino acid oxidase; NCBI: National Center for Biotechnology Information; NGF: nerve growth factor; PDE: phosphodiesterase; $\mathrm{pI}$ : isoelectric point; PLA $\mathrm{P}_{2}$ : phospholipases $\mathrm{A}_{2}$; PLB: phospholipase B; QC: glutaminyl-peptide cyclotransferase; SVMP: snake venom metalloproteinase; SVSP: snake venom serine protease; VNN2: vascular noninflammatory molecule 2. 


\section{Acknowledgments}

We thank members of the protein sequencing sections of Shanghai Institutes for Biological Sciences, Chinese Academy of Sciences. Computing resources were provided by the European Bioinformatics Institute (EBI), Wellcome Trust Sanger Institute (WTSI), co-produced animal reference genome database (http:// asia.ensembl.org/index.html), and the National Center for Biotechnology Information (http://www.ncbi.nlm.nih.gov).

\section{Availability of data and materials}

All data generated or analysed during this study are included in this published article and its additonal files.

\section{Funding}

This work was financially supported by grants from the Chongqing Forestry Reform and Development fund (no. Yu-lin-ke-tui -20192); project for public well-being funded by Chongqing Science and Technology Bureau (cstc2017chmsxdny0246); and Chongqing Normal University Fund projects (grant no. 19XLB006).

\section{Competing interests}

The authors declare that they have no competing interests.

\section{Authors' contributions}

$\mathrm{XY}$ and $\mathrm{QH}$ conceived this research. XN and SY designed experiments. QH participated in the design and interpretation of the data. XN performed experiments and analysis. XN wrote the paper and participated in the revisions of it. All authors read and approved the final manuscript.

\section{Ethics approval}

Not applicable.

\section{Consent for publication}

Not applicable.

\section{Supplementary material}

The following online material is available for this article:

Additional file 1. The information of protein identification from $D$. acutus venom determined by LC-MS/MS.

Additional file 2. Proteins identified from $D$. acutus venom.

\section{References}

1. Valenta J, Stach Z, Michálek P. Envenoming by crotalid snake chinese moccasin Agkistrodon acutus bite: a case report. Prague Med Rep. 2015; 116(2):155-60.

2. Qinghua L, Xiaowei Z, Wei Y, Chenji L, Yijun H, Pengxin Q, Xingwen S, Songnian $\mathrm{H}$, Guangmei $Y$. A catalog for transcripts in the venom gland of the Agkistrodon acutus: identification of the toxins potentially involved in coagulopathy. Biochem Biophys Res Commun. 2006 Mar 10;341(2):522-31.
3. Ouyang C, Huang TF. Purification and characterization of the fibrinolytic principle of Agkistrodon acutus venom. Biochim Biophys Acta. 1976 Jul 19; 439(1):146-53.

4. Wang WJ. Purification and functional characterization of AAV1, a novel P-III metalloproteinase, from Formosan Agkistrodon acutus venom. Biochimie. 2007 Jan;89(1):105-15.

5. Chen $\mathrm{RH}$, Chen YC. Isolation of an acidic phospholipase A2 from the venom of Agkistrodon acutus (five pace snake) and its effect on platelet aggregation. Toxicon. 1989;27(6):675-82.

6. Liu Q, Huang Q, Teng M, Weeks CM, Jelsch C, Zhang R, Niu L. The crystal structure of a novel, inactive, lysine 49 PLA2 from Agkistrodon acutus venom: an ultrahigh resolution, $A B$ initio structure determination. J Biol Chem. 2003 Oct 17;278(42):41400-8.

7. Xin Y, Dong D, Wang T, Li R. Affinity purification of serine proteinase from Deinagkistrodon acutus venom. J Chromatogr B Analyt Technol Biomed Life Sci. 2007 Nov 1;859(1):111-8.

8. Zheng Y, Ye FP, Wang J, Liao GY, Zhang Y, Fan QS, Lee WH. Purification, characterization and gene cloning of $\mathrm{Da}-36$, a novel serine protease from Deinagkistrodon acutus venom. Toxicon. 2013 Jun 1;67:1-11.

9. Wang WJ. Agglucetin, a tetrameric C-type lectin-like venom protein, regulates endothelial cell survival and promotes angiogenesis by activating integrin av $\beta 3$ signaling. Biochem Biophys Res Commun. 2008 May 2; 369(2):753-60.

10. Kong $Y$, Sun $Q$, Zhao Q, Zhang Y. Purification and characterization of a novel antiplatelet peptide from Deinagkistrodon acutus venom. Toxins (Basel). 2018 Aug 16;10(8):332.

11. 11. Yin W, Wang ZJ, Li QY, Lian JM, Zhou Y, Lu BZ, Jin LJ, Qiu PX, Zhang P, Zhu WB, Wen B, Huang YJ, Lin ZL, Qiu BT, Su XW, Yang HM, Zhang GJ, Yan GM, Zhou Q. Evolutionary trajectories of snake genes and genomes revealed by comparative analyses of five-pacer viper. Nat Commun. 2016 Oct 6;7:13107.

12. Tan $\mathrm{KY}$, Tan $\mathrm{NH}$, Tan $\mathrm{CH}$. Venom proteomics and antivenom neutralization for the chinese eastern Russell's viper, Daboia siamensis from Guangxi and Taiwan. Sci Rep. 2018 Jun 4;8(1):8545.

13. Malard V, Chardan L, Roussi S, Darolles C, Sage N, Gaillard JC, Armengaud J. Analytical constraints for the analysis of human cell line secretomes by shotgun proteomics. J Proteomics. 2012 Jan 4;75(3):1043-54.

14. Swanson SK, Washburn MP. The continuing evolution of shotgun proteomics. Drug Discov Today. 2005 May 15;10(10):719-25.

15. Santucci L, Candiano G, Bruschi M, D’Ambrosio C, Petretto A, Scaloni A, Urbani A, Righetti PG, Ghiggeri GM. Combinatorial peptide ligand libraries for the analysis of low-expression proteins: validation for normal urine and definition of a first protein MAP. Proteomics. 2012 Feb;12(4-5):509-15.

16. Selvaraju S, El Rassi Z. Targeting deeper the human serum fucome by a liquid-phase multicolumn platform in combination with combinatorial peptide ligand libraries. J Chromatogr B Analyt Technol Biomed Life Sci. 2014 Mar 1;951-952:135-42.

17. Tan HT, Ling LH, Dolor-Torres MC, Yip JWL, Richards AM, Chung MCM. Proteomics discovery of biomarkers for mitral regurgitation caused by mitral valve prolapse. J Proteomics. 2013 Dec 6;94:337-45.

18. Roux-Dalvai F, de Peredo AG, Simó C, Guerrier L, Bouyssié D, Zanella A, Citterio A, Burlet-Schiltz O, Boschetti E, Righetti PG, Monsarrat B. Extensive analysis of the cytoplasmic proteome of human erythrocytes using the peptide ligand library technology and advanced mass spectrometry. Mol Cell Proteomics. 2008 Nov;7(11):2254-69.

19. D'Ambrosio C, Arena S, Scaloni A, Guerrier L, Boschetti E, Mendieta ME, Citterio A, Righetti PG. Exploring the chicken egg white proteome with combinatorial peptide ligand libraries. J Proteome Res. 2008 Aug; 7(8):3461-74.

20. Farinazzo A, Restuccia U, Bachi A, Guerrier L, Fortis F, Boschetti E, Fasoli E, Citterio A, Righetti PG. Chicken egg yolk cytoplasmic proteome, mined via combinatorial peptide ligand libraries. J Chromatogr A. 2009 Feb 20;1216(8):1241-52.

21. Boschetti E, Bindschedler LV, Tang C, Fasoli E, Righetti PG. Combinatorial peptide ligand libraries and plant proteomics: a winning strategy at a price. J Chromatogr A. 2009 Feb 20;1216(8):1215-22. 
22. Fasoli E, Sanz L, Wagstaff S, Harrison RA, Righetti PG, Calvete JJ. Exploring the venom proteome of the african puff adder, Bitis arietans, using a combinatorial peptide ligand library approach at different $\mathrm{pHs}$. J Proteomics. 2010 Mar 10;73(5):932-42.

23. Van Vaerenbergh M, Debyser G, Devreese B, de Graaf DC. Exploring the hidden honeybee (Apis mellifera) venom proteome by integrating a combinatorial peptide ligand library approach with FTMS. J Proteomics. 2014 Mar 17;99:169-78.

24. Calvete JJ, Fasoli E, Sanz L, Boschetti E, Righetti PG. Exploring the venom proteome of the western diamondback rattlesnake, Crotalus atrox, via snake venomics and combinatorial peptide ligand library approaches. J Proteome Res. 2009 Jun;8(6):3055-67.

25. Wiśniewski JR, Zougman A, Nagaraj N, Mann M. Universal sample preparation method for proteome analysis. Nat Methods. 2009 May; 6(5):359-62.

26. Chen PC, Huang MN, Chang JF, Liu CC, Chen CK, Hsieh CH. Snake venom proteome and immuno-profiling of the hundred-pace viper, Deinagkistrodon acutus, in Taiwan. Acta Trop. 2019 Jan;189:137-44.

27. Lomonte B, Tsai WC, Ureña-Diaz JM, Sanz L, Mora-Obando D, Sánchez EE, Fry BG, Gutiérrez JM, Gibbs HL, Sovic MG, Calvete JJ. Venomics of New World pit vipers: genus-wide comparisons of venom proteomes across Agkistrodon. J Proteomics. 2014 Jan 16;96:103-16.

28. Liu CC, Lin CC, Hsiao YC, Wang PJ, Yu JS. Proteomic characterization of six taiwanese snake venoms: identification of species-specific proteins and development of a SISCAPA-MRM assay for cobra venom factors. J Proteomics. 2018 Sep 15;187:59-68.

29. Minton SA, Weinstein S. Geographic and ontogenic variation in venom of the western diamondback rattlesnake (Crotalus atrox). Toxicon. 1986;24(1):71-80.

30. Meier J. Individual and age-dependent variations in the venom of the fer-de-lance (Bothrops atrox). Toxicon. 1986;24(1):41-6.

31. He Y, Gao J, Lin L, Ma X, Ji X. Age-related variation in snake venom: evidence from two snakes (Naja atra and Deinagkistrodon acutus) in southeastern China. Asian Herpetol Res. 2014;5(2):119-27.

32. Aird SD, Aggarwal S, Villar-Briones A, Tin MMY, Terada K, Mikheyev AS. Snake venoms are integrated systems, but abundant venom proteins evolve more rapidly. BMC Genomics. 2015 Aug 28;16:647.

33. Xiong S, Huang C. Synergistic strategies of predominant toxins in snake venoms. Toxicol Lett. 2018 May 1;287:142-54.

34. Tasoulis T, Isbister GK. A review and database of snake venom proteomes. Toxins (Basel). 2017 Sep 18;9(9):290.

35. Olaoba OT, Dos Santos PK, Selistre-de-Araujo HS, Ferreira de Souza $\mathrm{DH}$. Snake venom metalloproteinases (SVMPs): a structure-function update. Toxicon X. 2020 Jul 21;7:100052.

36. Ogawa T, Oda-Ueda N, Hisata K, Nakamura H, Chijiwa T, Hattori S, Isomoto A, Yugeta $\mathrm{H}$, Yamasaki S, Fukumaki Y, Ohno M, Satoh N, Shibata $\mathrm{H}$. Alternative mRNA splicing in three venom families underlying a possible production of divergent venom proteins of the habu snake, Protobothrops flavoviridis. Toxins (Basel). 2019 Oct 9;11(10): 581.

37. Ogawa T, Chijiwa T, Oda-Ueda N, Ohno M. Molecular diversity and accelerated evolution of $\mathrm{C}$-type lectin-like proteins from snake venom. Toxicon. 2005 Jan;45(1):1-14.

38. Oshikawa K, Terada S. Ussuristatin 2, a novel KGD-bearing disintegrin from Agkistrodon ussuriensis enom. J Biochem. 1999 Jan;125(1):31-5.

39. Kini RM, Evans HJ. Structural domains in venom proteins: evidence that metalloproteinases and nonenzymatic platelet aggregation inhibitors (disintegrins) from snake venoms are derived by proteolysis from a common precursor. Toxicon. 1992 Mar;30(3):265-93.

40. Uzair B, Khan BA, Sharif N, Shabbir F, Menaa F. Phosphodiesterases (PDEs) from snake venoms: therapeutic applications. Protein Pept Lett. 2018;25(7).

41. Aird SD. Taxonomic distribution and quantitative analysis of free purine and pyrimidine nucleosides in snake venoms. Comp Biochem Physiol B Biochem Mol Biol. 2005 jan;140(1):109-26.

42. Sobrevia L, Yudilevich DL, Mann GE. Activation of A2-purinoceptors by adenosine stimulates $L$-arginine transport (system $y^{+}$) and nitric oxide synthesis in human fetal endothelial cells. J Physiol. 1997 Feb 15;499(1):135-40.
43. Zhang L, Wu WT. Isolation and characterization of ACTX-6: a cytotoxic L-amino acid oxidase from Agkistrodon acutus snake venom. Nat Prod Res. 2008 Apr 15;22(6):554-63.

44. Salama WH, Ibrahim NM, El Hakim AE, Bassuiny RI, Mohamed MM, Mousa FM, Ali MM. I-Amino acid oxidase from Cerastes vipera snake venom: isolation, characterization and biological effects on bacteria and tumor cell lines. Toxicon. 2018 Aug;150:270-9.

45. Danziger RS. Aminopeptidase $\mathrm{N}$ in arterial hypertension. Heart Fail Rev. 2008 Sep;13(3):293-8.

46. Mitsui T, Nomura S, Itakura A, Mizutani S. Role of aminopeptidases in the blood pressure regulation. Biol Pharm Bull. 2004 Jun;27(6):768-71.

47. Aird SD. Ophidian envenomation strategies and the role of purines. Toxicon. 2002 Apr;40(4):335-93.

48. Logtenberg MEW, Jansen JHM, Raaben M, Toebes M, Franke K, Brandsma AM, Matlung HL, Fauster A, Gomez-Eerland R, Bakker NAM, van der Schot S, Marijt KA, Verdoes M, Haanen JBAG, van den Berg JH, Neefjes J, van den Berg TK, Brummelkamp TR, Leusen JHW, Scheeren FA, Schumacher TN. Glutaminyl cyclase is an enzymatic modifier of the CD47- SIRPa axis and a target for cancer immunotherapy. Nat Med. 2019 Apr;25(4):612-9.

49. Jaiswal S, Jamieson CHM, Pang WW, Park CY, Chao MP, Majeti R, Traver D, van Rooijen N, Weissman IL. CD47 Is upregulated on circulating hematopoietic stem cells and leukemia cells to avoid phagocytosis. Cell. 2009 Jul;138(2):271-85.

50. Fischer $\mathbf{W H}$, Spiess J. Identification of a mammalian glutaminyl cyclase converting glutaminyl into pyroglutamyl peptides. Proc Natl Acad Sci U S A. 1987 Jun;84(11):3628-32.

51. Oberg KA, Ruysschaert JM, Azarkan M, Smolders N, Zerhouni S, Wintjens $R$, Amrani A, Looze Y. Papaya glutamine cyclase, a plant enzyme highly resistant to proteolysis, adopts an all-beta conformation. Eur J Biochem. 1998 Nov 15;258(1):214-22.

52. Song I, Chuang CZ, Bateman Jr RC. Molecular cloning, sequence analysis and expression of human pituitary glutaminyl cyclase. J Mol Endocrinol 1994 Aug;13(1):77-86.

53. Pohl T, Zimmer M, Mugele K, Spiess J. Primary structure and functional expression of a glutaminyl cyclase. Proc Natl Acad Sci U S A. 1991 Nov 15; 88(22):10059-63.

54. Huang J, Takeda Y, Watanabe T, Sendo F. A sandwich ELISA for detection of soluble GPI-80, a glycosylphosphatidyl-inositol (GPI)-anchored protein on human leukocytes involved in regulation of neutrophil adherence and migration-its release from activated neutrophils and presence in synovial fluid of rheumatoid arthritis patients. Microbiol Immunol. 2001;45(6):467-71.

55. Suzuki K, Watanabe T, Sakurai S, Ohtake K, Kinoshita T, Araki A, Fujita T, Takei H, Takeda Y, Sato Y, Yamashita T, Araki Y, Sendo F. A novel glycosylphosphatidyl inositol-anchored protein on human leukocytes: a possible role for regulation of neutrophil adherence and migration. J Immunol. 1999 Apr 1;162(7):4277-84.

56. Nitto T, Araki Y, Takeda $Y$, Sendo F. Pharmacological analysis for mechanisms of GPI-80 release from tumour necrosis factor-alpha-stimulated human neutrophils. Br J Pharmacol. 2002 Oct;137(3):353-60.

57. Vonk FJ, Casewell NR, Henkel CV, Heimberg AM, Jansen HJ, McCleary RJR, Kerkkamp HM, Vos RA, Guerreiro I, Calvete JJ, Wüster W, Woods AE, Logan JM, Harrison RA, Castoe TA, de Koning APJ, Pollock DD, Yandell M, Calderon D, Renjifo C, Currier RB, Salgado D, Pla D, Sanz L, Hyder AS, Ribeiro JMC, Arntzen JW, van den Thillart GEEJM, Boetzer M, Pirovano W, Dirks RP, Spaink HP, Duboule D, McGlinn E, Kini RM, Richardson MK. The king cobra genome reveals dynamic gene evolution and adaptation in the snake venom system. Proc Natl Acad Sci U S A. 2013 Dec 17;110(51):20651-6.

58. Santhosh MS, Hemshekhar M, Sunitha K, Thushara RM, Jnaneshwari S, Kemparaju K, Girish K. Snake venom induced local toxicities: plant secondary metabolites as an auxiliary therapy. Mini Reviews Med Chem. 2013 Jan;13(1):106-23.

59. Mohamed Abd El-Aziz T, Garcia Soares A, Stockand, JD. Snake venoms in drug discovery: valuable therapeutic tools for life saving. Toxins (Basel). 2019 Sep;11(10):564. 
60. Xiuxia L, Jiashu C, Yingna Z, Pengxin Q, Guangmei Y. Purification and biochemical characterization of $\mathrm{F} \mathrm{lla}$, a fibrinolytic enzyme from Agkistrodon acutus venom. Toxicon. 2001 Aug; 39(8):1133-9.
61. Zhang L, Cui L. A cytotoxin isolated from Agkistrodon acutus snake venom induces apoptosis via Fas pathway in A549 cells. Toxicol In Vitro. 2007 Sep; 21(6):1095-103. 